\title{
LA CONSTRUCCIÓN METAFÓRICA DE LA "EXCLUSIÓN" DESDE EL TRABAJO SOCIAL PROFESIONAL
}

\author{
(The metaphorical construction of "exclusion" from profesional social work)
}

\author{
Rosana Matos-Silveira ${ }^{1}$ \\ (Universidad de Granada, España)
}

\begin{abstract}
The purpose of this work is to publicize the professional thinking of a group of Spanish social workers on the construct of 'exclusion social' focusing on the perspective of metaphorical language. For the understanding of this perception the application of the focal group (focus group) was instrumental as a qualitative tool for research. This tool, from its interactive scope, led to a fluid discussion and the emergence of various and articulated metaphors when building, re-building and deconstructing meanings of certain beliefs and attitudes related to the phenomenon under study. It should be brought to attention that the social representations theory is presented as an explanatory mechanism to analyze the role played by these representations in the daily dynamics of professional practice.
\end{abstract}

Key words: social work, metaphor, social exclusion, social representations, focus group

\section{RESUMEN}

El propósito de este trabajo consiste en dar a conocer el pensamiento profesional de un colectivo de trabajadores/as sociales españoles/as sobre el constructo 'exclusión social' centrándose en la perspectiva metafórica. Para la comprensión de esta percepción fue fundamental como herramienta cualitativa de investigación la aplicación del grupo focal (focus group). Esta herramienta desde su alcance interactivo, propició una discusión fluida y el surgimiento de diversas y articuladas metáforas a la hora de construir y de-construir significados en torno a creencias y actitudes relacionados con el fenómeno estudiado. Resaltar que la Teoría de las Representaciones Sociales se presenta como mecanismo explicativo para analizar el papel que juegan estas representaciones en la dinámica cotidiana de la práctica profesional.

Palabras clave: trabajo social, metáfora, exclusión social, representaciones sociales, grupo focal.

\section{Introducción}

Este artículo tiene como finalidad dar a conocer las representaciones lingüísticometafóricas acerca de la "exclusión" social expresadas por un colectivo de trabajadores/as sociales de la ciudad de Granada, España. A través del estudio de estas metáforas nos acercamos a los conceptos abstractos verbalizados en cada discurso. Materializadas como

\footnotetext{
${ }^{1}$ Doctora en Antropología Social y Cultural por la Universidad de Granada, España. Trabajadora Social (PUC/MG-Brasil) y Antropóloga (UGR-España). Actualmente trabaja vinculada al Departamento de Trabajo Social y Servicios Sociales de la Facultad de Trabajo Social, Universidad de Granada, España. Investigadora del Grupo de Investigación SEPISE - UGR (Seminario de Estudios para la Intervención Social y Educativa). Miembro de la Asociación Trabajadores/as Sociales Sin Fronteras de Granada, España.
} 
constructo propio y construidos en base a experiencias cotidianas, expresan juicios particulares que edifican el pensamiento profesional sobre el fenómeno estudiado.

El contenido se organiza en cuatro momentos: el primer apartado, de carácter más teórico-conceptual reflexiona sobre la importancia y el papel que cumple el estudio de las metáforas a la hora de comprender el proceso cognitivo de representación de los seres humanos. También reflexiona sobre la cuestión de la pobreza/exclusión en su relación con el Trabajo Social y las políticas sociales de inclusión. La segunda parte, de cuño metodológico, da a conocer la aplicación y funcionalidad de los grupos focales como herramienta válida que facilita, a través de un proceso de interacción humana, la expresión de las representaciones, aquí transmitidas desde un enfoque lingüístico-metafórico. Posteriormente se presentan los resultados dando a conocer los distintos conjuntos metafóricos acompañados de citas textuales organizadas de forma analítica dimensional. Reflexionamos sobre los sentidos implícitos de cada conjunto, para identificar los aspectos subjetivos relacionados con el objeto de estudio, priorizando el análisis desde una dimensión social.

Invitamos para finalizar a un debate reflexivo-crítico sobre el papel de los/las trabajadores/as sociales no solamente como defensores y garantizadores de los derechos de ciudadanía sino también como visibilizadores y des-veladores de las contradicciones y nudos existentes en el ámago de las estructuras administrativas capitalistas.

\section{Perspectiva teórica: metáforas, representaciones sociales y pensamiento profesional}

La palabra metáfora (en griego, metaphorá) significa "transporte" y un proceso metafórico ocurre al efectuarse la transferencia de un determinado término hacia un contexto que no le es propio, o cuando se interpreta un campo de experiencias en función de otro campo ya conocido, uniéndose y cristalizándose este conocido con lo desconocido, lo tangible con lo menos tangible, lo familiar con lo nuevo (LAKOFF e JOHNSON, 1986; SOTO, 2001).

Desde una perspectiva metodológica la metáfora se presenta como una poderosa herramienta para estudios de cuño cualitativo porque profundiza en la comprensión de la naturaleza humana desde las acciones individuales y/o colectivas. Hasta los años setenta del siglo veinte las investigaciones se asociaban al campo de la lingüística como fenómeno semántico o léxico, pero a partir de esta fecha se viene ampliando significativamente las ramas de las ciencias sociales interesadas en una perspectiva de cuño más cognitivo para comprender y explicar la realidad, los procesos de pensamiento y de la inteligencia humana 
(ROJAS, 2005). Son estudios que resaltan la importancia de la naturaleza lingüística pero también de la no lingüística y la relación entre el conocimiento científico y el conocimiento común en confluencia con la sociedad y sus interacciones (RUSSELL, 1976, 1992, WEINER, 1984, LAKOFF e JOHNSON 1986, LAKOFF e TURNES, 1989; INDURKHYA, 1992). Desde esta óptica y relacionado con lo que aquí reflexionamos está el estudio realizado por SANTOS, NUNES e BAPTISTA (2015) sobre la representación social de la pobreza en la prensa argentina enfocada desde percepciones lingüística, discursiva e ideológica.

A grandes rasgos, existen diferentes tipos de metáforas: las narraciones y aquellas que ilustran el lenguaje oral o escrito a través de imágenes y comparaciones, las historias imaginarias, los proverbios, los chistes, los mitos, los cuentos de origen popular, las parábolas, etc. Pero su funcionalidad aplicada al estudio de las ciencias sociales se traduce como pedagógica, cuándo dan visibilidad e inteligibilidad a los conceptos abstractos; como analítico pedagógica, cuando permite analizar conceptos técnicos basados en experiencias propias y como experimental al posibilitar la transformación de estos conceptos abstractos en imágenes perceptibles y representaciones concretas y útiles (BUSTOS 2002; GALÁN y MORENO, J.2000; CUADRADO, 2004). Por su lado, LIZCANO, 1999) considera las metáforas como analizadores sociales centrales porque, al cristalizar las expresiones del lenguaje corriente y de los conceptos técnicos o científicos, permiten el acceso a los intereses, estrategias, inquietudes, conflictos, tanto sociales como culturales de los grupos o colectivos sociales estudiados.

En cualquier caso, nuestro interés aquí es destacar que la vida cotidiana está impregnada de metáforas y no solamente a través el lenguaje, sino también con la puesta en marcha del pensamiento y de la razón, y se conforman por las mismas relaciones existentes entre personas reconocidas como seres históricos y sociales. Es decir, los discursos metafóricos como procesos cognitivos reflejan el pensamiento y la comprensión acerca de un objeto en términos de otro de manera contextualizada puesto que las personas expresamos nuestro conocimiento del mundo y nuestra experiencia en él en función de nuestro lugar en la sociedad y del momento histórico y cultural que nos corresponda. Se elabora de esta manera un sistema conceptual que desempeña un importante rol en la definición de realidades cotidianas porque se construye colectivamente y desde la cotidianeidad ejerce un papel significativo a la hora de especificar, describir, conceptualizar las realidades (LAKOFF e JOHNSON, 1986). 
Las representaciones sociales de un objeto se generan así cuando las personas hacen referencia al mismo de forma explicativa y evaluativa, en base al conocimiento que tienen de la realidad que les rodea y por las explicaciones advenidas de procesos de comunicación y pensamiento social. Según MOSCOVICI (1979, p.27) son “entidades tangibles que circulan, se cruzan y se cristalizan sin cesar en nuestro universo cotidiano a través de una palabra, un gesto, un encuentro" y surgen desde contextos articulados, dinámicos, en movimiento como una red de ideas e imágenes cambiantes, fluidas e libremente interconectadas.

De ahí, al analizar en este trabajo un conjunto metafórico, hemos tenido en cuenta que:

$\checkmark$ El pensamiento expresado acerca de la "exclusión" no se limitó a la verbalización de opiniones o formas de pensar sino también a experiencias, percepciones e interacciones sociales en base a fuerza de la cotidianeidad profesional de las y los informantes.

$\checkmark$ El Trabajo Social en cuanto profesión y disciplina práctica ("saber experto"), contiene no solo conocimientos científicos, académicamente legitimados, sino también valores morales, reflexiones filosóficas y modelos de acción, construidos desde el conocimiento común y cotidiano.

$\checkmark$ La profesión abarca además habilidades y destrezas aprendidas en la formación y en la práctica ("saber-hacer") y desde este hacer profesional ante los procesos de exclusión, los/as trabajadores/as sociales elaboran continuamente nuevos significados y representaciones sobre las situaciones cotidianas vividas con los ciudadanos/as.

$\checkmark$ Estas representaciones se construyen en el contexto de las interacciones cotidianas con su propio grupo profesional, con profesionales de otras disciplinas y con el resto de elementos de la organización proveedora de servicio.

Por lo tanto, esta potencialidad que se vislumbra desde la praxis cotidiana del Trabajo Social, se entiende aquí como un proceso vital dinámico dónde se confluyen de forma dialéctica la acción y la reflexión. Por ello, tener como referencia la Teoría de la Representación Social permitió comprender, a través de las metáforas, cuáles son las fuerzas de las representaciones en la creación de realidades compartidas por los profesionales acercándonos así al papel que juegan en la dinámica cotidiana de la praxis y cómo la moldea. 


\section{La cuestión de la "exclusión" social y el Trabajo Social}

El término "exclusión" aparecerá a lo largo del texto entre comillas al entenderlo como un constructo que implica una forma concreta de ver e interpretar el mundo y la sociedad donde se articulan complejos y distintos fenómenos a nivel económico, político-institucional, jurídico, psíquico, posicionamientos ideológicos, etc.

La noción "exclusión” en el debate contemporáneo de las ciencias sociales cuestiona la visión economicista tradicional del concepto de "pobreza" presentándose como un fenómeno complejo, estructural y multifactorial que expresa múltiples procesos y realidades vitales. No obstante, a pesar de los intensos debates y publicaciones propagados en las últimas décadas, no se ha logrado un criterio consensuado para su definición. De hecho, CASTEL (1997) desde una mirada sociológica, prefiere hablar de procesos de desafiliación o desvinculación social y sus zonas de vulnerabilidad porque más allá de la ausencia de relación social, lo que ocurre es un conjunto complejo de relaciones particulares y fragilizadas construidas desde las redes de sociabilidad humanas, en contextos sociales e institucionales específicos.

En este sentido PAUGAM (2007) coincidiendo con SIMMEL (1986) nos recuerda que la "pobreza" y la "exclusión" son categorizaciones sociales que se construyen a partir del momento en que los "pobres" o "excluidos" reciben auxilio o deberían recibirlo de parte de los poderes públicos y no necesariamente porque sufren carencias y privaciones específicas:

(...) Las instituciones sociales no tienen en cuenta la miseria, pobreza o exclusión no
declarada, la que silenciosa, vive lejos de las mismas por miedo a exponerse
socialmente o por desconocimiento de sus propios derechos. Es a partir del
momento en que reciben asistencia cuando son clasificados como un grupo
caracterizado por la pobreza, por la exclusión: este grupo no permanece unido por la
interacción entre sus miembros, sino por la actitud colectiva que la sociedad como
totalidad adopta frente a él.

(SIMMEL, 1986, citado por PAUGAM, 2007, p.51).

Un análisis crítico semejante y aplicado al caso español nos aporta RAYA (2004) al considerar el concepto "exclusión" como un "constructo oportunista" o categoría creada para cumplir, reforzar y mantener, con su reiterada utilización, un estilo propio de trabajo científico-social y académico "absolutamente supeditado a políticas públicas, subsidiario, subsidiado y clientelar de las iniciativas en política social del Gobierno central, gobiernos autonómicos y locales, cuyos juegos políticos nacionales son en parte financiados por la Unión Europea, vía fondos estructurales” (p. 35). 
Enlazando con la cuestión del Trabajo Social, cabe observar que en la Unión Europea y en España en particular, la labor de esta profesión se desarrolla fundamentalmente en las Administraciones públicas o en organismos vinculados donde es el Estado quien realiza esta clasificación, gestionando y regulando en distintas formas el desarrollo de sus funciones a través de las políticas sociales, factor substantivo de contextualización de la profesión (NUNES, 2004) . De tal modo, en la división socio-técnica del trabajo colectivo, los profesionales venden su fuerza de trabajo ejerciendo actividades subsidiarias y auxiliares en esta "malla de reproducción de las relaciones sociales" implementando (más que formulando) medidas de política social mediadas por los servicios sociales. Cumplen de esta manera el rol de "ejecutores terminales de las políticas sociales" (NETTO, 1992, p.67) ejerciendo el control y difusión de la ideología de la élite capitalista dominante y de sus representantes en el Estado (IAMAMOTO, 2004).

Concretamente en España los profesionales vienen sufriendo en primera línea el impacto ideológico y material de la fuerte crisis estructural-capitalista-neoliberal en las situaciones vitales de los ciudadanos y ciudadanas usuarios/as de sus servicios. Experimentan la contradicción de, por un lado, responder a las exigencias del capital y por otro, participar aunque de forma subordinada, de respuestas a las necesidades legítimas de sobrevivencia de la clase trabajadora y subalternas (IAMAMOTO e CARVALHO, 1983).

Estas respuestas limitadas, emergenciales y deficitarias, consecuencia del desmantelamiento progresivo de la red pública de servicios, provoca en la categoría profesional malestares, indignación y fuerte sentimiento de impotencia. En base a este contexto hemos preguntado a un grupo de veinte y cinco profesionales con vasta experiencia en el campo de la "exclusión" cómo elaboran sus propias vivencias, creencias, sentimientos y actitudes ante esta realidad vivida desde la cotidianeidad. ${ }^{2}$ Percepciones y acciones influidas por una serie de representaciones provenientes de varios ámbitos específicos interrelacionados entre sí, y desde dónde se mueven diariamente: de las políticas sociales como discurso y como práctica, de los medios de comunicación, de la cultura dominante, del medio entorno de los

\footnotetext{
${ }^{2}$ Desde el marco del estudio denominado "Representaciones Sociales del Trabajo Social profesional sobre procesos de exclusión. Una investigación con profesionales de la ciudad de Granada, España" se han realizado cuatro grupos focales. Los profesionales advenidos de sectores públicos gubernamentales y no gubernamentales, tenían una amplia experiencia en intervención ante procesos de exclusión en distintos campos: comunitario, sanitario, penitenciario, educativo, diversidad funcional, cooperación al desarrollo y atención a distintas poblaciones: personas menores de edad, personas sin hogar, población gitana, inmigrantes, juventud en riesgo social, trabajadoras sexuales, etc.
} 
barrios o espacios donde desarrollan su labor y del contacto directo con los/as ciudadanos/as usuarios/as de los servicios que prestan.

\section{Enfoque metodológico: el Grupo Focal aplicado al estudio de las representaciones sociales}

La herramienta metodológica cualitativa utilizada y que ha potenciado la expresión de los discursos simbólicos metafóricos se denomina Grupo Focal. Coincidimos con ALVAREZGAYOL (2003) que es de gran valía esta herramienta para captar pensamientos, creencias, sentimientos, actitudes y reacciones acerca de un fenómeno porque favorece la interacción comunicativa e intercambio entre personas para la producción de un conocimiento propio en un espacio y tiempo determinados.

Los aspectos en los cuáles la puesta en marcha de los grupos focales posibilitó la adquisición de los datos aquí plasmados son los siguientes: facilitó la comprensión de los procesos de construcción de la realidad en torno a la "exclusión" de un determinado grupo social (en nuestro caso, de trabajadores/as sociales); visibilizó prácticas cotidianas, acciones y reacciones ante hechos concretos y eventos específicos además de comportamientos y actitudes frente a los mismos; diferenció las distintas representaciones, percepciones, creencias, hábitos, valores, restricciones, prejuicios, lenguajes y simbologías prevalentes en el tratamiento de una "cuestión de la exclusión" por profesionales que comparten trazos comunes y relevantes. Por último, visibilizó la percepción de diferentes perspectivas sobre este fenómeno permitiendo la comprensión de influencias e ideas compartidas por personas desde el cotidiano de las experiencias profesionales (GUTTI, 2005).

Para KITZINGER, MARKOVÁ e KALAMPALIKI (2004:239), el Grupo Focal es “un método que analiza la comunicación a través de conversaciones, permitiendo comprender los efectos recíprocos entre los símbolos, los discursos y modos de pensar, de palabra y de acción”. Lo que le distingue de los demás es su capacidad de facilitar la comprensión sobre cómo las representaciones sociales se construyen, transmiten, transforman y sostienen estos procesos comunicacionales.

Desde nuestro punto de vista, la riqueza de los elementos reflexivos construidos a partir de la realización de los grupos focales refuerza la validez de este método a la hora de estudiar las representaciones sociales, en nuestro caso expresadas a través de metáforas. Una riqueza 
que se produce porque, tal y como nos señala KITIZINGER (2004, pp. 299-301), permite explorar cuestiones diversificadas tales como

\begin{abstract}
la forma cómo los sujetos se dirigen unos a los otros y cómo se expresan, defendiendo y elaborando su identidad; el funcionamiento y el cómo utilizan y funcionan las anécdotas, metáforas y analogías en la discusión grupal; el valor del intercambio de diferentes hechos, expresiones e historias socialmente compartidas, etc.
\end{abstract}

Esta diversificación de opiniones, expuestas de forma desorganizada, discontinua, con interrupciones, verbalizaciones de anécdotas, risas, enfados y contradicciones es criticada por la psicología tradicional porque dificulta aislar y organizar los pensamientos y actitudes. No obstante, es justamente en estos "aspectos inconfortables" dónde reside su fortaleza y mayor riqueza ya que de esta manera, a través de una interacción auténtica entre los participantes, se da la posibilidad de recoger datos vivos, dinámicos validando la comprensión de las personas en acción, comportándose en interrelación.

En nuestro caso el proceso de discusión grupal sobre el significado de la "exclusión" tuvo un espacio y ámbito específicos: el mismo campo de los servicios sociales y de los proyectos sociales en el contexto de la práctica en las agencias donde desarrollan los informantes su profesión. Desde ahí iban elaborando su propia experiencia, sus propias creencias, sentimientos y actitudes en base a la interacción con los sujetos, desde el entorno del que forman parte las políticas y discursos sociales de las instituciones en que trabajan.

Resaltar que a la hora de seleccionar los/as informantes, se tuvo especial cuidado en combinar una cierta homogeneidad de perfiles profesionales para mantener la simetría de la relación de los componentes, y un mínimo de heterogeneidad para asegurar de esta manera, la diferencia necesaria en todo proceso discursivo. Invitamos a los grupos a trabajadoras/es sociales, con experiencia mínima de tres años de trabajo con colectivos en procesos de exclusión y que desarrollan su labor en diferentes organizaciones e instituciones sociales tanto públicas como privadas u ONGs.

En lo que se refiere al número de informantes han sido en total veinte y cuatro profesionales (seis en cada grupo), un número que consideramos ideal para garantizar la expresión libre de opiniones, la escucha activa y una real interacción entre los miembros. La duración aproximada de cada sesión fue de dos horas y media. Las indagaciones temáticas que orientaron la discusión han girado alrededor de los siguientes ejes temáticos: a) percepción sobre las dinámicas vitales de personas y colectivos en situaciones de exclusión; 
b) naturaleza de estos procesos; c) métodos de intervención utilizados; d) dificultades y logros percibidos a la hora de aplicar acciones por la inclusión; e) alternativas y propuestas de superación de las dificultades encontradas. En fin, la puesta en marcha del mencionado proceso metodológico tuvo como finalidad comprender desde la teoría de las representaciones sociales, lo que piensan y hacen las y los trabajadores sociales, y las relaciones que pueden entreverse entre la representación y a la acción profesional ante el fenómeno "exclusión", proceso cuyos resultados se presenta a continuación.

\section{Perspectiva analítica y discusiones}

La exposición de los datos y su análisis se divide en dos partes. En un primer momento se exponen las citas textuales que contextualizan las distintas metáforas acompañadas organizados en las siguientes dimensiones temáticas: estructural, Estado, políticas sociales y burocracia institucional, recursos sociales y desarrollo de la intervención profesional. Posteriormente se realiza un análisis interpretativo aproximado de los sentidos implícitos de cada conjunto metafórico.

\section{a) Dimensión estructural}

(GF1/TS2): Es que todas las sociedades tienen su cubo de basura y estamos hablando de i nuestro propio cubo de basura!![ tono enfático]: son nuestros viejos que no tienen quien los cuide, nuestros drogadictos o transeúntes de 40 años o más... eso porque, de alguna manera, la sociedad que tenemos: capitalista, neoliberal, los que entran en este carril, el sistema los va reproduciendo y nosotros, los trabajadores sociales, los acogemos. Y ahora, ¿que hacemos con ellos?

(GF1/TS6): "Lo que sé, es que realmente a ninguna Administración ni de derecha ni de izquierda le interesa llegar. Ni le van a votar, ni le van a plantear problemas, ni se van a organizar para montar números en contra de los políticos, ni de la administración. Las Administraciones y los politicos están completamente desorganizados, caóticos, lo único que hacen es taparlos. Lo único que hacen es, como blanquearlos para que no se vea."

Podemos ver que en este conjunto metafórico se plasman distintos factores que potencian procesos de "exclusión" que coinciden con el planteamiento analítico de Cabrera y Rubio (2008). Son los siguientes: factores estructurales macro-sociales como la distribución de la riqueza, limitaciones de acceso al mercado de trabajo y la calidad de los empleos; factores individuales, caracterizados por fracturas y quiebras relacionales que generan una importante franja de vulnerabilidad y exclusión social y los factores relacionados con la propia respuesta institucional deficitaria de atención global y preventiva. Según expresan los 
profesionales, el individuo en procesos de "exclusión" con sus distintas situaciones vitales se ve "atrapado" en un "carril" de una sola dirección empujado por la dinámica perversa de explotación capitalista neoliberal en su proceso de acumulación económica, basado en las desigualdades. Un "carril" que desemboca en un enmarañado de redes de recursos institucionales deficitarios fragmentados ("cubos de basura"), atomizados o sea, desconectados entre sí.

\section{b) Dimensión: Estado, políticas sociales y burocracia institucional}

(GF2/TS1): (...) "Es que son como engranajes que no terminan de encajar. Que no terminan. Eso, es como un quiero y no puedo... Es yo te digo el camino y tienes que ir además por ese camino. Como te escapes por... estas perdido. Y no es fácil."

(GF3/TS4): “La Administración además va engordando, engordando, engordando y tomando unas dimensiones también insoportables para un Estado..."

(GF1/TS1): ... "Es completamente irracional. O sea, mareamos al ciudadano. Yo creo que esta es una Administración de lo más burocrático.

(GF4/TS6): Es un cajón de sastre lo de asuntos sociales...

(GF4/TS2)... "Es que tienes que estar haciendo encajes de bolillo para encajar esas políticas

En este segundo conjunto metafórico los profesionales expresan una representación del Trabajo Social anclada en el modelo de gestión tecno-burócrata impuesto por una cultura de los servicios sociales donde las actuaciones profesionales a nivel preventivo y comunitario se ven desplazadas en general por normativas institucionales que priorizan la intervención individual-familiar. Son políticas y directrices que enaltecen la rentabilidad económica, imponiendo a los profesionales acciones de control paliativas y reproductoras de un sistema excluyente. El tercer sector, a su vez, también ejerce otras formas de clasificación y de exclusión, dado que los recursos son insuficientes para atender a las situaciones vitales de los ciudadanos y ciudadanas que viven estos procesos. Hecho que amplía significativamente la grieta entre el sistema público y el privado.

Los profesionales expresan sentimientos de indignación, inconformidad e impotencia ante la ineficacia de unas Administraciones públicas representadas como "engranajes" que no se encajan entre sí (descoordinación político-institucional), cada día más nutridas / "engordadas" por los trámites farragosos de una burocracia excesiva y confusa que duplica los 
servicios y "marean" a los/as ciudadanos/as haciéndoles perder su tiempo. Para no sucumbirse en este engranaje tecno-burócrata tan "desencajado" reivindican la puesta en marcha de procesos protocolizados e interdisciplinarios de coordinación institucional porque si no, y tal y como señala esta trabajadora social, "a medida que te alejas te tornas como más, diríamos burócratas... es la palabra... es muy fuerte... la palabra burócrata pero la verdad es que un trabajador social que está en los servicios sociales centralizados, o tiene una coordinación exhaustiva con el que está a pie de eso, o realmente la descoordinación es impresionante" (TS3/GF1).

\section{c) Dimensión: Recursos sociales}

(GF4/TS3): ... llevamos los trabajadores sociales y mucha más gente planteando la necesidad de una Ley Orgánica de Servicios Sociales que fuera el cuerpo normativo, que fuera el armazón sobre el que después se engancharan la dependencia, de la discapacidad, y no lo que ahora se ha hecho... El caso es que en vez de sacar esta Ley General como arquitectura, como estructura de todo lo demás, lo que se ha hecho es un brazo largo, largo y pretender poner un pegote sobre este brazo. Eso, es muy difícil encajarlo. (...) El brazo no puede ser más grande que el cuerpo entero y pretenden que lo sea y no puede ser.

(GF4/TS3): Se intenta vender [desde los medios de comunicación] una moto aunque no tenga motor.

(GF1/TS5): La atención social está medicalizada. Ahora mismo el sistema sanitario es una bisagra de muchos problemas sociales.

En este tercer conjunto metafórico, en la expresión simbólica "se ha hecho un brazo largo, largo y el brazo no puede ser más grande que el cuerpo entero" o "se intenta vender la moto aunque no tenga motor" se critica la falta de integralidad de las políticas sociales. Durante los discursos se referían por ejemplo al fuerte acento que se ha dado desde los poderes públicos al Sistema de Atención de la Dependencia ${ }^{3}$, uno de los instrumentos fundamentales para mejorar la situación de los servicios sociales en España. Considerada como una de las más ambiciosas en materia de cobertura social del Estado español, esta ley viene sufriendo en los últimos años serios problemas de financiación, encontrándose en una verdadera encrucijada. Una situación disfuncional que afecta a la eficacia de todo el "cuerpo orgánico" del sistema público.

\footnotetext{
${ }^{3}$ Esta Ley nació para atender en todo el territorio del Estado español a situaciones de dependencia y potenciar la promoción de la autonomía personal, la calidad de vida y la igualdad de oportunidades pero sin tener como base un cuerpo normativo integral y sostenible.
} 
Recientemente, con motivo de aprobación en junio de 2013 de la Ley de Racionalización y Sostenibilidad de la Administración Local (Ley de Reforma Local) se han llevado a cabo, a través del movimiento Marea Naranja una serie de movilizaciones. Estas buscan visibilizar e informar acerca de sus nefastos efectos y consecuencias para la ciudadanía y profesionales de lo social. El principal efecto es que los servicios sociales que hacen efectivos los derechos sociales de la ciudadanía serán sustituidos antes del 31 de diciembre de 2015 por mecanismos de "evaluación” de necesidades. La campaña de denuncia, promovida a nivel de todo el Estado se denomina: "Servicios Sociales en Peligro de Extinción: No a la Reforma Local”. La gravedad de los impactos de esta ley es muy alta para las profesiones relacionadas con lo social, principalmente el Trabajo Social.

\section{d) Dimensión: Desarrollo de la intervención profesional}

(GF2/TS4): Tenemos que trabajar con la exclusión, porque nadie quiere, te hace moverte y tienes que ir continuamente formando... jesto es tan cambiante! [Expresión reflexiva (...) La sociedad va avanzando y quedarte estancado... es como coger el árbol por las hojas.

(GF3/TS2): "Yo veo un montón de profesionales que se dejan la piel, diríamos en levantar situaciones que son terribles, para que después las gentes que salen de la cárcel por ejemplo, no encuentren su sitio en la sociedad."

(GF1/TS1): (...) yo creo que el hacer de puente cuando falta el paso este de la coordinación, de la estructura formal es importante; seguimos siendo ese puente que está bien, que ojalá no perdiéramos esta función porque siempre va a hacer falta alguien que haga de puente y vaya abriendo vía. Me parece que esa es la esencia de nuestro trabajo.

(GF1/TS2): Pues seguimos con este ciclo de favores hasta que hagamos una piña y nos sentemos todos/as y presionamos desde la base... ¿Pero por qué tengo que pedir el favor a una gente que institucionalmente tiene la obligación de atender?

(GF1/TS1): En fin, yo pienso también que la Administración en este país no oye. Y hacen programaciones y leyes y tal sin realmente oír a los profesionales.

(GF4/TS3): "Desde luego yo creo que la fotografía de los elementos de la realidad tiene una importancia muy grande. ¡Que vean que somos capaces de hacer esta fotografía de la realidad!! [Tono enfático] No sabremos cómo resolverla, pero esto al menos. Vamos, que no es una cosa ison, mil cosas, que están ahi! [Tono enfático], y además, que mueven sentimientos,

En este último conjunto metafórico la dimensión "desarrollo de la intervención profesional" se ubica en un contexto de fuerte crisis económica, social y política de los últimos seis años. A las situaciones extremas de pobreza y exclusión se une otra relacionada 
con situaciones multiproblemáticas familiares de hombres y mujeres que han vivido en un entorno vital razonablemente estable y que ahora se encuentran vulnerables económicamente. Son personas que carecen de recursos psicológicos para acomodarse a esta nueva situación, después de perder su trabajo y cierta seguridad económica; las que sufren la precarización del empleo, inmigrantes expulsados del mercado laboral, etc. Van perdiendo las seguridades sobre las cuáles basaban sus vidas, de sus familias y de sus relaciones en general. Es en este escenario de "exclusiones" donde las/os trabajadoras/es sociales se sienten capacitados para "fotografíar" la realidad; se "dejan la piel ante una "Administración que no escucha" representada como soberana y mecánica, que con directrices institucionales presiona hacia la aplicación de medidas y acciones emergenciales paliativas.

\section{Consideraciones finales}

Hemos constatado que, de la construcción lingüístico-discursiva de las representaciones sociales acerca de la "exclusión" construida metafóricamente por los/as trabajadores/as sociales se han aflorado "teorías" implícitas cotidianamente materializadas en su práctica profesional que dan pié a la apertura de un amplio debate dentro de la misma categoría profesional. Por ejemplo, estos profesionales son conscientes de su participación en la producción y reproducción de las relaciones sociales de un sistema capitalista y opresor: (...) "somos técnicos y también parte del sistema, lo reproducimos". No obstante, a pesar de la gran riqueza discursiva a la hora de "fotografiar" la cuestión de la exclusión y sus causas, en los discursos escasea la problematización acerca de su participación ético-política. Predomina el discurso de la queja y la sensación de impotencia frente al creciente desmantelamiento del Estado de Bienestar en España.

Desde nuestro punto de vista, queda por profundizar y abrir un nuevas discusiones que reflexiones sobre el uso del poder específico de los profesionales como agentes de cambio, la problematización de sus responsabilidades o funciones específicas, la explicitación de posiciones ideológico-políticas entre otras cuestiones. De todas formas, hay que considerar que esta representación negativa expresada en los discursos está vinculada a una severa crítica hacia el sistema actual de políticas sociales: 
Parece que tenemos una visión muy negativa de la exclusión, de que no tienen remedio y para qué vamos a hacer nada, y no es así... Si la exclusión es crónica e irrecuperable es en función de tal como está organizado el sistema de servicios sociales, las políticas sociales en este momento. No por lo sea en si misma. ¿Me explico? Como profesionales no pensamos que es así y siempre va a ser así, ¿sabes lo que te quiero decir? (TS2, GF4).

En España y en los países europeos en general a raíz de la crisis sistémica de los últimos años el papel del Estado Social como garantizador de los derechos de ciudadanía viene retrocediéndose vertiginosamente con drásticas consecuencias vitales para la clase trabajadora y subalterna. A pesar de la implantación de varios Planes Nacionales de Inclusión, en la práctica las Administraciones van dejando muchas de sus responsabilidades y obligaciones en manos de una iniciativa privada débil, atomizada y sin suficientes recursos para hacer frente a una demanda social cada vez más creciente.

Las Organizaciones No Gubernamentales son las que hacen de manera paralela el papel de "pioneras en la atención a la pobreza y la exclusión social, estando siempre en un primer plano, atendiendo las necesidades de los colectivos con especiales dificultades, interviniendo con nuevos colectivos y estableciendo metodologías innovadoras de intervención social" (GALINDO, 2008, p. 374). No obstante, también es cierto que este paralelismo unido a la carencia de una real coordinación protocolizada a nivel institucional refuerza la dicotomía actualmente existente entre el sistema público y el sistema privado español (MATOSSILVEIRA, 2011).

En este contexto, los/as trabajadores/as sociales, ubicados en primera línea de aplicación de las políticas de inclusión se sienten desafiados a re-diseñar y a re-construir un proyecto ético-político acorde con los principios y valores de la profesión y así garantizar a la ciudadanía su acceso a los derechos fundamentales. Esperamos que la comprensión de la articulación que se ha generado entre estos profesionales y las mismas representaciones se configure como una herramienta crítica y reflexiva sobre su que-hacer cotidiano ante el complejo fenómeno exclusión/inclusión, uno de los núcleos más significativos en torno al que desarrollan su labor cotidiana.

Recebido em: março de 2016

Aprovado em: maio de 2016

rosanadm@ugr.es 


\section{Referencias bibliográficas}

ABRIC, J.C. Metodología de recolección de las representaciones sociales. In: Prácticas Sociales y Representaciones Sociales. México: Ediciones Coyoacán, 1996.

ÁLVAREZ-GAYOU, J.L. Cómo hacer investigación cualitativa. Fundamentos y Metodología. Barcelona: Paidós, 2003.

BARBERO, J.M. El Trabajo Social en España. Zaragoza: Mira, 2002.

BUSTOS, E. La metáfora y la filosofía contemporánea del lenguaje. Revista de Filosofía, n.19, 2002.

CABRERA, J.P.; RUBIO. Las personas sin hogar hoy. Revista del Ministerio de Trabajo e Inmigración, 2008. n. 75, p.51-74.

COSÍN, P. Trabajo Social: Globalización y Posmodernidad. Sociotam, 2007.vol.17, n. 2.

CUADRADO, G. Metáfora, ciencia y cultura: propuesta de una nueva tipología para el análisis de la metáfora científica. [Documento online] http://www.aelfe.org/documents/text7_cuadrado.pdf_CConsulta: 01-12- 2014]

FALEIROS, V. P. Trabajo Social, ideología e método. Buenos Aires: ECRO, 1972.

FALEIROS, V. P. Desafios do Serviço Social na era da globalização. Revista Serviço Social e Sociedade. São Paulo: Cortez, 1999.

GALÁN, C.; MONTERO, J. El discurso tecnocientifico: la caja de herramientas del lenguaje. Madrid: Arco Libros, 2000.

GALINDO, A.L. Eficacia de las políticas de inclusión social en la región de Murcia. En: Hernández Pedreño (Org.), Exclusión Social y Desigualdad, 2008, p.365-382.

GUYENNOT, C. L’insertion. Un problème social. Paris: L'Harmattan, 1998.

GUTTI, B. A. Grupo focal na pesquisa em Ciencias Sociais e Humanas. Brasilia: Liber Libro, 2005.

HAMZAQUI, M. Trabajo Social Territorializado. Las transformaciones de la acción pública en la intervención social. Valencia: NAU Libres. 2005.

HEALY, K. Trabajo social: perspectivas contemporáneas. Madrid: Morata, 2001.

IAMAMOTO, M.; CARVAlHO, R. Relaciones Sociales y Servicios Social en Brasil. São Paulo: Cortez Editora, 1982.

IAMAMOTO, M. As dimensões ético-políticas y teórico-metodológicas no Serviço Social Contemporâneo. En: La cuestión social y la formación profesional en el contexto de las nuevas relaciones de poder y la diversidad latinoamericana. San José, Costa Rica: ALAETS/Escuela de Trabajo Social, 2004, pp. 17-50. 
INDURKHAYA, B. Metaphor and Cognition: Studies in Cognitive Systems. Dordrecht, The Netherlands: Kluwer Academic Publishers, 1992.

KITZINGER, J.; MARKOVÁ, I; KALAMPALIKI, N. Qu'est-ce que les focus groups? Bulletin de psychologie, 2004. vol. 57 (3), p. 237-243.

KITIZINGER, J. . Le sable dans l'huître: analyser des discussions de focus group. Dan Bulletin de Psychologie. 2004. vol. 57, n.3, p. 299-307.

LAKOFF, G. and JOHNSON, M. Metáforas de la vida cotidiana. Barcelona: Cátedra, 1986.

LAKOFF, G.; TURNES, M. More Than Cool Reason: A Field Guide to Poetic Metaphor, Chicago: University of Chicago Press, 1989.

SANTOS, L.G.J; NUNES, A.T.; Baptista, R.T.L.M. Metáforas conceituais na construção da representação social de pobreza pela mídia argentina. Cadernos de Linguagem e Sociedade, 2015. vol.16, n.1, p. 173-190.

LIZCANO, E. La metáfora como analizador social, Empiria, 1999, n.2, p. 29-60.

MATOS-SILVEIRA, R. Trabajo Social en España: contextos históricos, singularidades y desafíos actuales. Katálisis, 2013. vol. 10, n.2, p. 101-109.

MATOS-SILVEIRA, R. Representaciones sociales del trabajo social profesional sobre procesos de exclusión. Investigación con profesionales de la ciudad de Granada, España. Departamento de Trabajo Social y Servicios Sociales. Granada: Universidad de Granada, 2011. Tesis Doctoral. http://digibug.ugr.es/bitstream/10481/19441/1/20059474.pdf

MERINO, L.; RAYA E. Política Social y Trabajo Social: algunas cuestiones sobre el sistema de provisión de servicios sociales personales. En: Martínez, M.J. (Org.) Para el trabajo social. Aportaciones teóricas y prácticas. Granada: Maristán, 2000.

MOFFAT, K. Vigilancia y gobierno del receptor de bienestar. In Chambón y otros. (Org.) Foucault y el trabajo social. Granada: Maristán/EUTS Linares, 2001, pp. 315-343.

MOSCOVICI, S. El Psicoanálisis, su imagen y su público. Buenos Aires: Huemul, 1979, p. 27-44.

NETTO, J. P. (1992). Capitalismo Monopolista y Servicio Social. São Paulo: Cortez.

NUNES, M.H. Serviço social em contexto: Política Social e Serviço Social. Trabajo Social Global, 2004, $\mathrm{n}^{\circ} 1$ (1), 59-79.

ROJAS DE ESCALONA, B. El análisis de las metáforas: una estrategia para la comprensión y el cambio en el contexto organizacional. Sapiens [online], 2005, v.6, n 2, p. 53-62.

RUSSELL, S.W. Computer understanding of metaphorically used verbs. American Journal of Computational Intelligence, 1976, vol. 2, p. 15-28. 
RUSSELL. Metaphoric coherence: Distinguishung verbal metaphor from "anomaly". Computational Intelligence, 1992, v.8. n.3, p. 553-574.

SIMMEL, G. Estudio sobre las formas de socialización, Madrid: Alianza, 1986.

SOTO, J. El lenguaje metafórico como potenciador de la competencia comunicativa en el aprendizaje y la enseñanza de lenguas, 2001 [Documento online] Disponible: $\mathrm{http}: / /$ lacasadeasterion.homestead.com/v1n4metaforahtml [Consulta: 22-04.06]

YAZBEK, M.C. O significado sócio histórico da profissão. Serviço Social: Direitos Sociais e Competências Profissionais. Brasilia: CFESS/ABEPSS., 2009.

WEINER, J.E. A knowledge representation approach to understanding metaphors. Computational Linguistics, 1984, v.10, n.1, p. 1-15.

ZAMANILLO, M.T. El incierto acontecer en el Trabajo Social: logros, vacíos y proyectos. En: Revista Acciones e Investigaciones Sociales, 2000, n.11, p. 175-202.

ZAMANILLO, M.T.; MARTÍN, M.T. La responsabilidad política del Trabajo Social. Revista Trabajo Social Global, 2011, v.2, n.3, p. 97-115. 